УДК 159.9

DOI: $10.17223 / 17267080 / 66 / 3$

\title{
Я.К. Смирнова
}

Алтайский государственный университет (Барнаул, Россия)

\section{Ориентировочная основа совместной деятельности дошкольников}

\begin{abstract}
На примере дошкольного возраста рассматривается феномен ориентировочной основы совместной деятельности как один из механизмов организации и регуляции индивидуальных операций в групповом действии. Показано, что в ориентировочной основе совместных действий дошкольников отражается программа, которая представляет собой совокупность предвидимых действий, объединенных заданием, выполняемых в определенной временной и пространственной последовательности. Подтверждается, что в ориентировочной части действий осуществляется анализ изменений процесса деятельности, в соответствии с этими изменениями в реакции происходит регуляция хода осуществления программы, выявляются несоответствия программного и процессуального действий.

Ключевые слова: ориентировочная основа действия; ориентировка; ориентировочная основа совместных действий; структура совместной деятельности; функииональные компоненты регуляция деятельности; дошкольный возраст.
\end{abstract}

Феномен ориентировочной основы действий представляет собой систему репрезентаций субъекта о цели, программе, средствах и условиях осуществления предстоящего или выполняемого действия (А.Н. Леонтьев, П.Я. Гальперин, Н.Ф. Талызина, В.В. Давыдов, А.В. Запорожец, З.А. Решетова, А.Г. Лидерс). П.К. Анохиным, Э.А. Астратяном, Д.А. Бирюковым отображена функциональная роль ориентировочной части действия. Так, общая задача ориентировки - это ориентация в ситуации с сигнальными признаками новизны, когда «изменения внешней среды выходят за пределы возможностей автоматического приспособления» [1].

В научных исследованиях ориентировка рассматривается как деятельность, направленная на обследование окружающего, процесс превращения этой деятельности из внешней во внутреннюю и собственно психическая деятельность по регуляции поведения человека (А.Н. Леонтьев, П.Я. Гальперин, А.Р. Лурия). На современном этапе изучена роль ориентировки в произвольной регуляции деятельности (А.В. Запорожец, П.К. Анохин, Д.А. Бирюкова, Д.Б. Годовикова, Е.И. Бойко), ориентировка анализируется как система условий, на которые ориентируется человек при выполнении действия (В.П. Зинченко), в том числе в ходе ознакомления с новой ситуацией (Д.Б. Годовикова). Б.М. Теплов, В.Д. Небылицин выделили типологические особенности ориентировочных рефлексов. Ориентировочная основа 
действия осмыслена как синпрактическая поисковая деятельность, в процессе которой выделяются компоненты ситуации и существенные взаимоотношения между ними (Н.Н. Поддьяков). Важным является отображение планомерности и поэтапности формирования ориентировочного действия (П.Я. Гальперин, Н.Ф. Талызина, В.В. Давыдов, А.И. Подольский, Ю.А. Самарин, Е.И. Бойко, Л.С. Цветкова). Отдельно произведен анализ ориентировочной основы действий в рамках проблемы «латентного обучения» (I. Deese, D. Thistlethwaite, Д.Б. Годовикова), показана роль речи и словесной инструкции как «дополнительной афферентации» в процессе ориентировочного действия, словесной организации ориентировки (А.Р. Лурия, О.К. Тихомиров, Д.Б. Эльконин, Т.В. Ендовицкая, М.И. Лисина), охарактеризованы дезориентирующая основа деятельности (А.Н. Поддьяков), образно-понятийная модели деятельности (А.А. Крылов, А.И. Худяков).

Теория ориентировочной основы действий дополняется А.Т. Велфордом [2], В.П. Зинченко [3] в изучении образов, регулирующих предметные действия человека, которые обозначаются авторами как «концептуальная модель деятельности». Показано, что концептуальная модель деятельности это та ориентировочная основа действий, которая является системой образа среды и образа действия, объединенных в единый структурный элемент, на основе которого происходит управление действием. В.П. Зинченко обосновывает, что информационная модель представляет собой совокупность информации об объекте управления, системе управления, среде, самом субъекте, средствах отображения информации. Информационная модель специальным образом упорядочена, чтобы обеспечить быстрое и удобное восприятие и работу с полученными данными. В свою очередь, концептуальная модель - это некие сведения, полученные ранее при обучении или отложившиеся в памяти. Оба типа данных объединяются в едином процессе переработки информации и управляющих действий [Там же].

Д.А. Ошанин [4] вводит понятие оперативного образа ситуации. Так, ориентировочная основа действия задает оперативный образ (Д.А. Ошанин), что, в свою очередь, формирует информационную и концептуальную модель (в терминах В.П. Зинченко). Вводится термин «информационная основа деятельности» для обозначения совокупности информации, характеризующей предметные и субъективные условия деятельности, позволяющей организовать ее в соответствии с вектором «цель-результат» (В.Д. Шадриков).

При этом на современном этапе остается недостаточно исследованным социально-психологический аспект изучения ориентировочной основы совместной деятельности как группового процесса, определяющего результативность совместной деятельности. На данном этапе анализ социальнопсихологического контекста изучения феномена представлен исследованиями ориентировки в структуре совместной деятельности (Е.И. Гамова, А.С. Чернышев, Р.С. Семенов). В концепции организованности малых групп ориентировка осмыслена в качестве социально-психологических механизмов 
актуализации субъектных свойств группы и оценки группой включенности индивидов в совместную деятельность [5-6].

А.Л. Журавлев считает, что ориентировочная основа совместной деятельности способствует формированию группового состояния, а именно состояния предактивности (преддеятельности) [7].

Рассматривая проблему ориентировки в совместной деятельности, А.С. Чернышев, А.Н. Лутошкин отмечают, что ориентировка должна включать как диагностику состояния организационных отношений, так и прогностическую оценку их проявления в будущей деятельности [5-6]. Ориентировка совместной деятельности группы, по их мнению, выполняет функцию некой «инвентаризации», т.е. анализа условий ситуации, группового потенциала, согласования желаемого результата.

O.М. Савчик [8] отмечает, что различными авторами ориентировочный этап совместной деятельности включается как начальная стадия групповой динамики: ориентировка в ситуации, межличностных отношениях, групповой задаче, способах ее решения, формирование установки на совместное действие (И.П. Волков); ориентировка как условие создания волевого единства групповых действий, выяснение форм деятельности (Т. Санталайнен, Э. Воутилайнен, П. Поренне, Й. Ниссинен, О.М. Савчик и др.); поиск оптимальных способов взаимодействия (М. Вудкок и Д. Фрэнсис); ориентировка членов группы в характере действий друг друга и поиск взаимоприемлемого межличностного поведения в группе, поиск членами группы оптимального способа решения задачи (Б. Такмен).

В исследованиях С.В. Сарычева, А.С. Чернышева ориентировочная часть совместной деятельности определяется как один из психологических механизмов надежности группы в напряженных и экстремальных ситуациях совместной деятельности, когда значительно увеличивается «удельный вес» ориентировочной части совместной деятельности в группах с более высоким показателем по параметру «организованность» [9].

В организации и регуляции индивидуальных операций в совместном действии В.В. Рубцов выявил такую особенность этапа поиска решения задачи, как ориентировочно-пробующие действия [10].

Большой вклад в исследование взаимосвязи типов ориентировки с уровнем организованности группы и результативностью совместной деятельности внесла Е.И. Гамова [11-12]. По ее мнению, сокращение ориентировки служит критерием степени освоенности деятельности группой, а также критерием выработки накопления группового опыта совместной деятельности.

Ориентировка (ориентировочная основа совместной деятельности) оперативный образ предстоящей совместной деятельности, в котором групповой субъект осуществляет пробно-поисковую активность (исполнение), разрабатывается схема действий в соответствии с поставленной задачей, анализируются условия предстоящей деятельности, с которой ранее он никогда не сталкивался или сталкивался в других условиях.

Таким образом, ориентировочная основа совместной деятельности была исследована как система представлений группы о цели, плане и средствах 
осуществления предстоящей деятельности. Ориентировочная основа совместной деятельности является фактором, который направляет деятельность группы при выполнении задачи. В процессе ориентировки можно проанализировать оценку способностей, потенциала членов группы, их вклад и действия в процессе исполнительской части, предвидеть протекание исполнительской части совместной деятельности (С.В. Сарычева, А.С. Чернышева).

Актуальным становится анализ социальных аспектов организации регуляции деятельности, что требует моделирования не отдельных признаков, например параметров группового взаимодействия, не их разнородной совокупности, а типологической композиции структуры взаимосвязи данных параметров регуляции структуры совместной деятельности.

Формулируется задача - изучить на фоне определенных личностнотипологических особенностей регуляции деятельности (Э.А. Голубева, В.Н. Азарова) проявления произвольности через усвоение ребенком средств и способов организации своего поведения в совместной деятельности (Л.С. Выготский, Д.Б. Эльконин, А.Л. Вегнер, Е.О. Смирнова), формирование и усвоение способов организации индивидуальной и совместной деятельности.

Необходимо отметить, что в ходе возрастного развития наблюдаются специфические изменения взаимоотношений исполнительских и ориентировочных действий, а также превращение первых во вторые. А.В. Запорожцем были обобщены результаты изучения ориентировочных компонентов деятельности детей в процессе усвоения новых действий [13]. Он доказал, что на более поздних генетических ступенях возрастного развития ориентировочные реакции отделяются от исполнительских и фаза ознакомления с условиями задания начинает предшествовать фазе практического его выполнения. Такое усложнение и совершенствование ориентировочной деятельности приводит к формированию более адекватных образов воспринимаемого, что обнаруживается, например, в повышении эффективности различения и воспроизведения воспринимаемых форм. Иначе говоря, сенсорный эффект - полнота и адекватность перцептивного образа - зависит от особенностей ориентировочной деятельности ребенка в отношении воспринимаемого. Также А.В. Запорожец отмечает, что ориентировочные компоненты какой-либо целостной деятельности выполняют функцию уподобления, моделирования тех материальных или идеальных предметов, с которыми ребенок действует, и приводят к созданию адекватных представлений или понятий о конкретных предметах, а специальная организация ориентировочной деятельности играет существенную роль в процессе руководства различными видами деятельности детей.

Эксперименты Т.В. Ендовицкой, Я.3. Неверович и других исследователей показали: после того как у испытуемого складывалась система ориентировочных реакций, хаотические пробы исчезали, ошибочные движения тормозились до достижения отрицательного практического эффекта как не соответствующие имеющемуся образу, и последующее поведение быстро приобретало адекватный обстоятельствам характер[14]. 
Изучены ориентировочные перцептивные действия у детей различных дошкольных возрастов в процессах осязательного, кинестетического и зрительного восприятия (3.М. Богуславская, Т.О. Гиневская, Я.3. Неверович). Исследования П.Я. Гальперина показали, что в ходе сенсорного обучения первоначально развернутые ориентировочно-исследовательские действия постепенно сокращаются, их эффекторные звенья оттормаживаются и весь процесс постепенно переносится извне вовнутрь, в движение фокуса внимания по полю восприятия [1]. Именно от ориентировочно-исследовательской деятельности детей в отношении предметных условий задачи зависит эффективность решения задач в наглядно-действенном плане. Так, Г.И. Минская обнаружила четыре типа ориентировочно-исследовательской деятельности [15]. При первом типе (примитивно-хаотическом) ориентировочные реакции на условия задачи отсутствуют; при втором типе ребенок полностью сосредоточен на цели, но не на условиях и средствах; третий тип ориентировочной деятельности (зрительно-двигательный) направлен на исследование не только цели, но и условий и средств; четвертый тип носит чисто зрительный характер. Г.И. Минской обнаружено, что тип ориентировочно-исследовательской деятельности значительно влияет на эффективность решения. При этом во всех возрастных группах количество правильно решенных задач растет по мере перехода от примитивно-хаотической ориентировки к зрительно-двигательной.

Главное, что было выявлено учеными при изучении соотношения ориентировочной и исполнительной фаз поведения, - это типы самой ориентировки в заданиях и их изменение как на протяжении усвоения данного действия, так и в возрастном плане. На первых этапах усвоения ориентировка носит развернутый, внешний характер, включает «пробующие» движения, перемещения предметов, с которыми предстоит действовать, и т.п. На последующих этапах она постепенно свертывается, уходит во внутренний план и становится незаметной для постороннего наблюдателя.

Особая актуальность исследования продиктована тем, что именно ситуация совместной деятельности позволит проследить в динамических ситуационных условиях роль ориентировочной основы действия в регуляции и коррекции цели и средств на индивидуальном уровне и уровне согласования совместных действий.

В ситуации совместной деятельности можно экспериментально зафиксировать особенности регуляторных процессов, разворачивающиеся в групповых действиях через основные звенья системы саморегуляции (ориентировка, планирование, программирование, моделирование, оценка результатов), а также регуляторно-личностные свойства, инструментальные свойства личности, такие как самостоятельность, надежность, гибкость, степень сформированности отдельных компонентов деятельности, их содержательное наполнение и отношения между ними, в том числе ориентировочную основу действия как один из универсальных механизмов согласования активности личности и требований совместной деятельности и достижения принятой индивидуальной и групповой цели. 
В ориентировочной части действия можно проследить роль оперативного образа в совместной деятельности, т.е. специфического образа объекта, формирующегося в процессе совместного выполнения конкретного действия (группы действий) с ним, предназначенного и приспособленного специально не для индивидуальных, а для совместных действий (группы действий).

Именно оперативность отражения ситуации совместной деятельности обеспечивает пластичное, гибкое переключение с отражения одних свойств объекта на отражение других его свойств в зависимости от групповой задачи, тем самым осуществляя регуляторную функцию психического отражения.

Ориентировочным звеном действий в исходной форме является развернутое обследование ситуации, имеющее внешнее двигательное выражение, затем это обследование сворачивается, и ряд специфических превращений становится симультанным воспроизведением в образе особенностей данной ситуации. Появление этого образа предвосхищает осуществление исполнительного звена действий, что отображает сложное взаимодействие в произвольных движениях ориентировочного и исполнительного звена.

Таким образом, ориентировочные действия первоначально возникают и развиваются как органическая часть практической деятельности субъекта в тесной связи с ее исполнительской частью (А. Н. Леонтьев [16]).

В опоре на представления А.Р. Лурия [17] необходимо проследить, как в ситуации совместной деятельности произвольная регуляция способствует дифференциации приоритетных стимулов по степени важности для решения определенной задачи, а также определению программы целесообразных движений, входящих в состав совместных действий, и торможению нецелесообразных, задает выбор лишь существенных для деятельности программ действий.

Н.Ф. Талызина [18] подчеркивает, что ориентировочная часть обеспечивает не только правильное исполнение действия, но и рациональный выбор одного из множества возможных исполнений. Человек, выполняя ориентировочную часть действия, обеспечивающую указанные функции, опирается при этом на ориентировочную основу действия. Эффективность ориентировочной части действия, по Н.Ф. Талызиной, не зависит от формы, в которой она представлена (материальная, материализованная, внешнеречевая и т.д.), но существенно зависит от полноты отражения в ней условий, объективно определяющих успешность действия.

В связи с этим необходимо отметить, что именно ориентировочная основа действий помогает осуществлению отбора нужной информации в ситуации совместной деятельности, обеспечению избирательных программ действий и сохранению постоянного контроля над их протеканием.

Эмпирически необходимо проследить, как ориентировочная основа действий не только на индивидуальном, но и на уровне совместной деятельности способствует избирательному характеру сознательной деятельности и произвольной регуляции в ситуации совместных действий. 
П.Я. Гальперин указывает, что ориентировочную основу деятельности удается смоделировать, «материализовать» в тех или иных пространственных свойствах и отношениях:

- определении содержания совместных действий;

- установлении способов выполнения совместных операций;

- анализе и организации внешних условий выполнения совместных операций;

- распределении совместных операций во времени.

Мы исходили из предположения, что изучение механизмов ориентировочной основы действий поможет уточнить представления о механизмах торможения, своевременного переключения с нецелевых на целевые приоритеты совместной деятельности. Именно устойчивость целевого приоритета на протяжении всей совместной деятельности определит ее организацию и результативность.

Нами была выдвинута гипотеза, что в ситуации совместной деятельности возможно проследить, как ориентировочная основа деятельности встраивается в процесс выбора доминирующих процессов, создание гибких регулятивных звеньев совместной деятельности за счет постановки подцелей и использования специальных психических орудий организации совместной деятельности.

Исходя из данных предпосылок, целью исследования стал анализ функциональной структуры системы регулирования индивидуальной и групповой деятельностью дошкольников, в том числе проявления ориентировочной основы действия в регуляции совместной деятельности. Основной задачей в рамках проблемы, на решение которой направлено исследование, становится отображение в модели внутренней структуры регуляции совместной деятельности, регуляторных свойств ориентировочной основы деятельности.

В структуре регуляции совместной деятельности дошкольников необходимо отобразить ориентировочную часть деятельности:

- характеристику афферентного синтеза условий деятельности, анализ внутренних и внешних условий совместной деятельности, сличение реальных условий и субъективно принимаемой модели условий, задание программы совестной деятельности;

- формирование представлений о контролируемых параметрах, критериях успешности;

- возможность коррекции функционирования различных регуляторных звеньев деятельности, обеспечение пластичности, когда этого требуют условия совместной деятельности;

- обеспечение надежности и устойчивости функционирования регуляторных звеньев совместной деятельности;

- собственно специфику типов ориентировки совместной деятельности (самостоятельность программирования, моделирования, оценки, коррекции своей активности). 


\section{Процедура исследования}

Эмпирическая выборка. В исследовании приняли участие 136 детей раннего возраста (5-7 лет). Исследование проводилось в организованных микрогруппах по 5-7 человек.

Методы и методики эмпирического исследования:

1. В ходе исследования создавались экспериментальные условия совместной деятельности дошкольников, в которых производилась экспертная оценка методом шкалирования и ранжирования поведенческих индикаторов проявления регуляции совместной деятельности детей дошкольного возраста. Отдельное внимание уделялось фиксации ориентирвочной части совместной деятельности. Среди эмпирических индикаторов, разработанных и апробированных нами ранее в исследовании совместной деятельности дошкольников [18], были предложены следующие индикаторы:

- программирование совместных действий (умение сознательно подчинить свои действия правилу, способность четко задавать, завершать и корректировать программу деятельности, компоненты, связанные с программированием произвольных действий (возможность усвоения и следования заданной или выработанной программе), возможность создания собственной стратегии деятельности, снижение устойчивости программы деятельности, завершенность программы деятельности, упрощение программы, инертное построение ее элементов, поэлементное выполнение программы, интенференция, неустойчивая тенденция к расширению программы, умение ориентироваться на заданную систему требований, необходимость помощи и контроля в организации деятельности, понимание инструкции, способность организовывать и поддерживать свою деятельность, ориентировочная основа деятельности, трудности в ориентировке в условиях или требованиях задания (неполный анализ условий задач));

- исполнительные действия (компоненты, связанные с избирательной регуляцией произвольных действий: инертность действий, импульсивность действий, возможность избирательного реагирования на существенные для решения задачи стимулы, возможность переключения с одного элемента программы на другой, возможность переключения с программы на программу, возможность устойчивого следования усвоенной серийной программе, трудности оттормаживания стереотипов, опережающее поведение, гибкость (дополнительные действия, не относящиеся к инструкции), инертность, трудность переключения с одного задания на другое, импульсивность, трудности вхождения в задания);

- контроль и оценка результата (количество ошибок, количество попыток, сбои, видит ли свои ошибки, ориентация на ошибки партнера, достижение результата, подавление нежелательных двигательных реакций, подчинение правилам);

- речевая регуляция совместной деятельности (наличие ориентировочных и организующих речевых высказываний, наличие «внешней» речевой регуляции, обращенность речи к партнеру, к взрослому, наличие высказываний, 
стимулирующих групповую деятельность, умение задать речевую инструкцию партнеру, выполнение словесной деятельности в нестандартных условиях, сформированность речевой регуляции в планировании деятельности, словесное обобщение собственных действий, словесное планирование (внешнее, а затем внутреннее) предстоящих действий как высший этап словесной регуляции, использование в речи личных местоимений множественного числа - «нас», «мы», использование в речи личных местоимений - «я», «мне» и др.);

- организация совместной деятельности (поэтапное регулирование поведения партнеров, оценка действий партнера, помощь партнеру, наличие советов и реплик по поводу работы, работает один / работает вместе с партером, следит за работой партнера, распределяет деятельность между партнерами, согласованные или индивидуальные действия, операции совместные / индивидуальные, ориентировочная основа совестной деятельности, позиция лидера / ведомого / исполнителя, реагирует действием на советы партнера и др., умение завершить программу деятельности, в том числе вовремя прекратить выполнение действия, переключиться на выполнение другого задания).

- мотивация (необходимость дополнительной стимуляции, эмоциональное состояние, сопротивление, негативизм, отказ от выполнения задание, положительный / отрицательный контакт).

2. Стандартизированные психодиагностические методики для фиксации данных: методика «Сделаем вместе» (И.Б. Дерманов), методика проблемных ситуаций «Одень куклу», «Мозаика», социометрическая методика «Секрет» (Т.А. Репина).

3. Методы математико-статистической обработки: факторный анализ, регрессионный анализ. Обработка проводилась при помощи статистического пакета SPSS 22.0.

\section{Результаты исследования}

Для нахождения модели композиции структуры совместной деятельности применен факторный анализ методом главных компонент с варимакс вращением (для ортогональности факторов). Процедура позволила представить структурную композицию функциональных звеньев совместной деятельности членов дошкольного коллектива.

Было получено трехфакторное решение структуры совместной деятельности дошкольников $(\lambda=43)$.

1-й фактор $(\lambda=22)$ - блок ориентировочной основы совместной деятельности и контроля совместных действий. Фактор представляет собой характеристики ориентации дошкольников во взаимодействии (положительная направленность и продолжительность контакта, наличие заинтересованности дошкольников в предложенной совместной деятельности, оказание помощи партнеру, совместная работа с партнером, отслеживание работы партнера), информационное отображение критериев необходимости коррекции 
совместных действий (количество попыток и сбоев выполнения совместных действий, количество ошибочных совместных действий, способность увидеть собственные ошибки и оценить ошибки партнера, негативная реакция при нарушении распределений действий между партнерами), речевая регуляция и контроль совместных действий (реакция дошкольников действием на советы партнера, употребление личностных местоимений множественного числа, речь дошкольников обращена к партнеру, присутствуют советы реплики по поводу совместной работы и работы партнеров).

2 -й фактор $(\lambda=11)$ - блок моделирования, программирования и удержания программы совместных исполнительных действий. Данный блок в структуре совместных действий дошкольников раскрывается через такие индикаторы, как присутствие понимания дошкольниками инструкции, распределение действий между партнерами, преобладание совместных или индивидуальных операций, необходимость помощи и контроля в организации деятельности, характеристики групповых ролей «лидер» / «исполнитель».

3-й фактор $(\lambda=10)$ - блок мотивационного интереса и контроля согласования совместных действий. Данный блок можно осмыслить через критерии понимания или непонимания дошкольниками инструкции «вместе», характеристики личностного контакта между дошкольниками, наличие согласованных или индивидуальных действий, критерий достижения результата, интерес к совместной деятельности, присутствие регулирования поведения партнера.

Данная факторная структура раскрывает основные компоненты регуляции совместной деятельности. Анализ результатов исследования позволяет сделать вывод, что в структуре ориентировочной основы совместных действий дошкольников можно зафиксировать следующие компоненты: принятие цели совместной деятельности, обеспечение субъективной модели значимых условий, программирование исполнительских действий, систематизация субъективных критериев достижения цели, контроль и оценка реальных результатов, решение о коррекции системы регулирования.

В дальнейшем при помощи регрессионного анализа среди индикаторов выявлены предикторы, определяющие характеристики процесса совместной деятельности дошкольников.

Важнейшим параметром для анализа стал критерий достижения результата в ходе совместной деятельности. Выявлено, что достижение результата совместной деятельности дошкольниками $\left(R^{2}=0,958, p=0,0001\right)$ зависит от полноты ориентировки $(\beta=0,277)$, преобладания совместных операций над индивидуальными $(\beta=0,194)$, согласованности индивидуальных действий с групповыми $(\beta=0,089)$, присутствия помощи партнерам $(\beta=0,099)$, наличия согласия дошкольников с общегрупповым мнением $(\beta=0,284)$, возможности отстаивания своего мнения $(\beta=0,227)$, характера эмоционального состояния дошкольников в совместной деятельности $(\beta=0,371)$. При этом препятствовать достижению результата совместной деятельности будет увеличение числа попыток и сбоев $(\beta=-0,078)$, а также 
снижение речевой регуляции совместной деятельности: дошкольники не понимают инструкции «вместе» $(\beta=-0,166)$, речь не обращена к партнеру $(\beta=-0,032)$.

Другой важной задачей стало определение роли ориентировки в организации совместной деятельности. Так, ориентация дошкольников в действиях партнера, наличие согласованности действий влияют на вероятность появления негативной реакции на нарушение распределения средств совместной деятельности, в том числе распределения конкретных материалов совместной деятельности $\left(R^{2}=0,510, p=0,008\right)$. Данный критерий также влияет на оказание помощи партнеру $\left(R^{2}=0,610, p=0,0001\right)$. Ориентировка в действиях партнера выступает условием контроля и распределения средств совместной деятельности. Согласованность индивидуальных и совместных действий дошкольников выступает предиктором наличия организации, регуляции групповой деятельности на уровне операций $\left(\mathrm{R}^{2}=0,516\right.$, $\mathrm{p}=0,002)$.

Работать совместно с партнером будут дошкольники, которые откликаются на советы партнера и реагируют на совет партнера действиями, принимают помощь от партнеров, допускают контроль действий со стороны других дошкольников, сразу понимают инструкцию деятельности $\left(R^{2}=0,728\right.$, $p=0,0001)$.

Подтверждается роль речевого контроля как важнейшего компонента ориентировочной части совместной деятельности. Так, количество ошибок в совместной деятельности дошкольников $\left(R^{2}=0,949, p=0,0001\right)$ возрастает, если дошкольники не используют личностные местоимения множественного числа $(\beta=-0,131)$, не дают реплик по поводу работы партнеров ( $\beta=-0,230)$. При этом речь, обращенная к партнеру, снижает количество ошибок $(\beta=0,151)$. Принятие инструкции является предиктором проявления обращенной к партнеру речи, наличия речевого сопровождения и реплик по поводу действий для партнера, присутствия речи, обращенной к взрослому $\left(R^{2}=0,672, p=0,0001\right)$. Нарушение понимания инструкции «вместе» влияет на увеличение отрицательной направленности контакта $\left(R^{2}=0,707, p=0,0001\right)$, а также снижает вероятность достижения результата деятельности $\left(R^{2}=0,475, p=0,004\right)$. Наличие речевого контроля в процессе выполнения деятельности влияет на преобладание совместных действий над индивидуальными $\left(R^{2}=0,335, p=0,037\right)$. Подтверждается, что ориентировка включает в себя словесную регуляцию совместной деятельности в форме прямого побуждения партнера к действию, обозначения предмета совместной деятельности, направляющей инструкции для ответной реакции партнера, обозначения обобщенного действия, а также в форме внешнего положительного стимулирования или оттормаживания нежелательных действий партнера. Речевая ориентировка выступает как переход к внутренней словесной регуляции, словесной организации и планированию предстоящих совместных действий совместно со взрослым или со сверстниками.

Выявлено, что количество ошибок $\left(R^{2}=0,949, p=0,0001\right)$ возрастает при снижении контроля в форме импульсивности $(\beta=-0,240)$, трудностях 
переключения с одного задания на другое $(\beta=0,368)$. Снижает количество ошибок присутствие регулирования дошкольниками поведения партнера $\left(\beta=0,150, R^{2}=0,949, p=0,0001\right)$.

В исследовании подтверждается роль ориентировочной части совместной деятельности в согласовании исполнительных действий. Дезорганизующие дополнительные действия, не относящиеся к инструкции $\left(R^{2}=0,657, p=0,0001\right)$, будут появляться у дошкольников со сниженным контролем в форме импульсивного $(\beta=0,141)$, опережающего поведения $(\beta=-0,199)$. Действия, не относящиеся к инструкции, характерны для дошкольников, которые испытывают трудности в ориентировке $(\beta=-0,129)$, отслеживании поведения партнера $(\beta=-0,131)$, понимании инструкции $(\beta=0,141)$. Вместе с тем расширение программы действий, не относящихся к инструкции, будет направлено на повышение эффективности совместной деятельности в случае, если это стало следствием совместной работы с партнерами ( $\beta=0,084)$, обнаружения дошкольником собственной ошибки $(\beta=0,125)$, отстаивания своего мнения $(\beta=0,091)$. Можно предполагать, что оперативная ориентировка в действиях партнера определяет характер, последовательность, способы действий, направленных на достижение цели в динамических условиях.

Контролирующая функция ориентировочной основы совместной деятельности будет проявляться в том, что отслеживание действий партнера снижает инертность, тугоподвижность действий дошкольников $\left(R^{2}=0,334\right.$, $p=0,05)$. Дошкольникам, которые следят за работой партнера, дают советы и реплики по поводу совместной деятельности, требуется меньшее количество попыток для выполнения задания и достижения результата $\left(R^{2}=0,807\right.$, $p=0,0001)$. Трудность переключения с одного задания на другое влияет на возрастание количества ошибок $\left(\beta=0,353, R^{2}=0,949, p=0,0001\right)$. Ориентировочная часть совместных действий обеспечивает соответствие между запрограммированным ходом деятельности, конечным результатом и реальным ходом совместной деятельности, возможность своевременной оперативной коррекции программы индивидуальных и совместных действий.

Понимание дошкольниками общей цели совместной деятельности будет зависеть от наличия регулирования действий партнера, совместных действий с партнером и низкой импульсивности $\left(R^{2}=0,739, p=0,0001\right)$. Данные подтверждают, что способ действия определяется условиями, в которых задана цель совместной деятельности. Принятие цели выступает важнейшим параметром эффективности совместной деятельности.

Единство ориентировки и мотивационного компонента совместной деятельности будет проявляться в том, что положительная направленность контакта в процессе совместной деятельности дошкольников $\left(R^{2}=0,793\right.$, $p=0,0001)$, заинтересованность дошкольников в продолжении совместной деятельности $\left(R^{2}=0,931, p=0,0001\right)$ будет зависеть от того, насколько дошкольник следит за действиями партнеров и реагирует ли он действиями на их реплики. Принятие и понимание дошкольниками инструкции снижает отрицательный эмоциональный настрой, сопротивление, негативизм 
в совместной деятельности $\left(R^{2}=0,477, p=0,004\right)$. Проблемная задача, задавая некоторую ситуацию совместной деятельности, не только побуждает ребенка к конкретному действию, но и создает контекст проявления его инициативы и поддерживает ориентировку как важнейший организационный компонент совместной деятельности.

В ориентировочной основе совместной деятельности на первое место выступает не только анализ способа индивидуальных и совместных действий в конкретной ситуации, но и анализ задания инструкции, совместный поиск средств и способов ее выполнения, речевой контроль совместных действий. Группа, в которой сформирована ориентировка в совместных действиях, обладает устойчивостью к изменениям условий и более эффективно достигает результат.

В процессе совместной деятельности с помощью речевой ориентировки и ориентировки на уровне конкретных действий выделяются процессуальные и результативные признаки: информационные признаки, с ориентацией на которые выполняются действия; информация, используемая в процессе выполнения совместных действий; результативные признаки, которые дают информацию о параметрах результата, по которым происходит сопоставление с целью деятельности (отдельных действий). В совместной деятельности ориентировочную часть задает цель либо в форме критерия значимости результативных признаков, либо в форме задания, где ведущая роль отводится процессуальным признакам.

Ориентировка выступает как система условий, на которые должны ориентироваться члены группы в совместной деятельности для согласования операционально-технической стороны.

Ориентировочная основа совместной деятельности может быть представлена как последовательность выполнения (алгоритм) операций и система сведений (ориентиров), на которую должен опираться каждый член группы при выполнении индивидуальных и совместных действий.

Полученные данные подтверждаются содержательным анализом совместной деятельности дошкольников. Качественный анализ взаимодействия дошкольников в экспериментальной ситуации показывает, что ориентировочная основа действий в условиях группового взаимодействия обеспечивает активное изучение задания и только потом - переход к выполнению системы исполнительных, рабочих процедур.

\section{Обсуждение результатов}

Результаты исследования подтверждают, что за счет ориентировочной части совместных действий достигается согласованность операционально-технической стороны деятельности с объективными условиями проблемной ситуации совместной деятельности дошкольников. Ориентировочная основа совместной деятельности включает афферентный синтез условий деятельности, средств, состава деятельности, контроля (отслеживание совпадения предмета с представлением о продукте и с предметом и 
продуктом партнеров) и оценку деятельности (сличение продукта с индивидуальной и групповой целью).

Ориентировочная основа действий (ее обобщенность, полнота, способ получения информационной основы деятельности) оказывает влияние на результативность совместной деятельности дошкольников.

Было выявлено, что ориентировка начинает разворачиваться чаще всего в ситуации неопределенности, перед которой стоит группа, а именно уже при постановке общей цели совместной деятельности на индивидуальном уровне, затем при постановке задач перед группой.

Ориентировочная часть совместной деятельности выступает компонентом надежности группы за счет опосредования построения исполнительной части совместной деятельности.

Ориентировка группы в совместной деятельности по своему психологическому содержанию характеризуется как процесс исследования условий предстоящей совместной деятельности, проектирования средств исполнения. Ориентировочная основа совместной деятельности является структурной частью деятельности, направляющей и реализующей процессы взаимодействия и согласования действий членов группы.

Ориентировочная основа действий в условиях группового взаимодействия проявляется в обращении внимания партнеров на отношения между объектами с помощью словесных указаний. Эффективность совместной деятельности будет зависеть от способности дошкольников прибегать к более непосредственным приемам организации ориентировки (например, не только речевое указание, но и указание действием на сопоставляемые предметы), что позволяет совместно анализировать отношения между объектами деятельности и использовать эти отношения для решения задач.

Можно выделить главные функции ориентировочной основы совместной деятельности: уяснение проблемной ситуации, выделение объекта действий в актуальной задаче, выбор стратегии и метода индивидуальных и совместных действий, регуляция выполнения деятельности.

В ориентировочной части совместных действий отображается уточнение не только конечного образа цели, но и промежуточных звеньев совместных действий, их соотношения.

\section{Заключение}

Исследование позволило не только рассмотреть и операционализировать феномен ориентировочной основы действий на уровне индивида, но и проследить специфику трансформации ориентировки на уровне организации совместной групповой деятельности.

Трудности произвольной регуляции совместной деятельности у дошкольников проявляются в том, что первое знакомство с обстоятельствами эксперимента, ориентировочная деятельность носят хаотический характер, и отдельные исследовательские реакции не связаны друг с другом. Затем происходит выявление существенных компонентов. Несформированная 
ориентировочная основа действий присутствует у дошкольников, которые сразу приступают к осуществлению движений без предварительной ориентировки в ситуации и без взаимодействия с членами коллектива.

На данном возрастном этапе сформированные внешние ориентировочно-исследовательские действия помогают дошкольнику предвосхищать пути и результаты действий практических, сообразуясь с теми правилами и ограничениями, которые задают и условия деятельности, и другие участники коллектива. Ориентировочная основа деятельности функционально обеспечивает избирательность, распределение совместных действий, целенаправленность внешнего управления процессом совместных действий, неотложность оперативного реагирования на изменение внешних и внутренних условий и средств деятельности, выбор совместных средств деятельности, эффективность оперативного планирования, непосредственное воплощения программы совместных действий в условиях сложной динамики окружающей среды.

Специфика ориентировочной части совместной деятельности в дошкольном возрасте будет проявляться в том, что именно состав действий диктует динамику ориентировки. Так, ведущее значение в ориентировке принадлежит процессуальным признакам и меньшее - результативным.

Исследование подтверждает противоречия, которые связаны с необходимостью отображения роли ориентировочной основы деятельности в оперативном планировании в условиях совместной деятельности при постановке задач разного уровня новизны, сложности и неопределенности. Ориентировочная часть совместной деятельности группы исследована с точки зрения переосмысления и расширения представлений о критериях результативности и способах оптимизации совместной деятельности, а также их интеграции с критериями произвольной регуляции деятельности. Данные подтверждают, что на основе анализа содержания ориентировки возможны достоверное прогнозирование хода и результативности предстоящей совместной деятельности групп, отбор и комплектование групп для выполнения сложных практических задач.

Дальнейшей практической задачей является внедрение программ развития ориентировочной основы совместной деятельности с целью эффективного согласования групповой деятельности, развития произвольной регуляции деятельности и исполнительной части действий у дошкольников.

За счет организации совместной деятельности достигаются:

- экстериоризация действия в материальной или материализованной форме, использование дошкольниками ранее сформированных индивидуальных действий в совместной деятельности (в перцептивной и умственной форме);

- возможность усвоить содержание действия, совместно осуществлять объективный контроль за выполнением каждой входящей в действие операции;

- для обобщения действия отработка типовых случаев применения данного действия в решении групповой задачи; 
- создание условий развития действия как внешнеречевого после того, как все содержание действия оказывается усвоенным. На этом этапе, где все элементы совместного действия представлены в форме внешней речи, действие проходит дальнейшее обобщение, но остается еще неавтоматизированным и несокращенным;

- представление с помощью речевого контроля новых типовых ситуаций, которые на предыдущем этапе не могли иметь места. В совместной деятельности может присутствовать полный речевой контроль, а в дальнейшем действие начинает выполняться с пропуском в речевой форме отдельных операций;

- формирование действия во внешней речи про себя. Приняв умственную форму, действие очень быстро начинает сокращаться и автоматизироваться во внутренней речи, что способствует развитию произвольности необходимых навыков.

Данная логика отражает, как через ориентировочную основу совместной деятельности возможно интенсифицировать формирование и закрепление индивидуально выработанных навыков.

Практическая значимость полученных результатов:

- знание структуры, функций и основных характеристик ориентировочной части совместных действий позволит моделировать наиболее рациональные виды организации совместной познавательной деятельности дошкольников, эффективно усваивать в групповой форме запрограммированные виды познавательной деятельности;

- выделены условия, которые обеспечивают планомерное становление у дошкольников сложной структуры ориентировочной части совместных действий, исполнительного и надысполнительных ее компонентов (целевых компонентов ориентировочной части действий при освоенной исполнительной части ориентировки): развитие ориентировочно-исследовательской деятельности детей в отношении предметных условий решения совместной групповой задачи; поэтапное формирование форм ориентировочной части совместных действий (материальной, материализованной, внешнеречевой и т.д.), полноты отражения в них условий, объективно определяющих успешность группового действия;

- основные совместные действия составляют этапы индивидуального усвоения действия, каждый из которых характеризуется совокупностью изменений основных свойств (параметров) действия: совместные действия, как и индивидуальные, должны стать обобщенными, сокращенными и освоенными, проходя через переходные состояния;

- формирование мотивационного компонента усвоения знаний, умений, навыков через совместную деятельность у дошкольников. Наличие мотивов - необходимое условие для принятия дошкольниками задачи и выполнения адекватной ей деятельности. Из данных исследования видно, что в групповой деятельности должно быть обеспечено создание проблемных ситуаций, разрешение которых возможно с помощью только совместного действия; 
- представлена модель прогнозирования хода и результативности предстоящей совместной деятельности;

- уточнены и опробованы методы групповой диагностики ориентировки для оценки регуляторных функций у дошкольников;

- произведено выделение конкретных индикаторов и методов диагностики сформированности произвольной регуляции действий у дошкольников в ситуации совместной деятельности с целью определения склонности к поведенческим нарушениям, снижению контролирующих функций, воспроизведению дезадаптивных форм поведения в групповом взаимодействии.

\section{Лumepamypa}

1. Гальперин П.Я. Введение в психологию : учеб. пособие для вузов. М. : КДУ, 1999. 332 с.

2. Welford A.T. On the human demands of automation: Mental work conceptual model, satisfaction and training. // Industrial and business psychology. 1961. Vol. 5. P. 182-193.

3. Зинченко В.П. К вопросу о формировании ориентирующего образа // Ориентировочный рефлекс и ориентировочно-исследовательская деятельность. М. : Изд-во АПН РСФСР, 1958. С. 333- 339.

4. Ошанин Д.А. Психологические вопросы регуляции деятельности М. : Педагогика, 1973. $208 \mathrm{c}$.

5. Чернышев А.С. Социально-психологические основы организованности первичного коллектива (на материалах исследования молодежных групп и коллективов) : автореф. дис. ... д-ра психол. наук : 19.00.05. М., 1980. 65 с.

6. Чернышев А.С., Сарычев С.В., Лунев Ю.А. Аппаратурные методики психологической диагностики группы в совместной деятельности. М. : Изд-во Ин-та психологии РАН, $2005,189 \mathrm{c}$.

7. Журавлев А.Л. Психология совместной деятельности. М. : Изд-во Ин-та психологии $\mathrm{PAH}, 2005.628 \mathrm{c}$.

8. Савчик О.М. Ориентировочная основа совместной деятельности как условие создания волевого единства группы // Вестник полоцкого государственного университета. Серия Е: педагогические науки. 2006. № 11. С. 77-82.

9. Сарычев С.В., Чернышев А.С. Социально-психологические аспекты надежности группы в напряженных ситуациях совместной деятельности. Курск, 2000.

10. Рубцов В.В. Основы социально-генетической психологии. М. : Ин-т практ. психологии ; Воронеж : МОДЭК, 1996. 384 с.

11. Гамова Е.И. Исследование социально-психологических аспектов ориентировочной основы совместной деятельности малых групп // Ломоносов-2009 : материалы докладов XVI Междунар. науч. конф. студентов, аспирантов и молодых ученых МГУ. М. : МАКС Пресс, 2009. С. 128-132.

12. Гамова Е.И. Ориентировка в структуре совместной деятельности и ее влияние на результативность совместной деятельности малых молодежных групп // Научный журнал КубГАУ : политематический сетевой электронный научный журнал Кубанского государственного аграрного университета. 2012. № 5 (79). URL: http://ej.kubagro.ru/2012/05/pdf/49

13. Запорожец А.В. Избранные психологические труды : в 2 т. М. : Педагогика, 1986. T. II: Развитие произвольных движений. 296 с.

14. Ендовицкая Т.В. Влияние организации ориентировочной деятельности на объем внимания у детей // Доклады АПН РСФСР. 1957. № 3. С. 75-79. 
15. Минская Г.И. Переход от наглядно-действенного к рассуждающему мышлению у детей дошкольного возраста : автореф. дис. ... канд. пед. наук (по психологии) / Акад. пед. наук РСФСР, Науч.-исслед. ин-т психологии. М., 1954. 14 с.

16. Леонтьев А.Н. Проблемы развития психики. М. : Изд-во Моск. ун-та, 1981. 584 с.

17. Лурия А.Р., Цветкова Л.С. Нейропсихологический анализ решения задач. Нарушения процесса решения задач при локальных поражениях мозга. М. : Просвещение, 1966. $291 \mathrm{c.}$

18. Талызина Н.Ф. Управление процессом усвоения знаний. М. : Изд-во Моск. ун-та, 1984. $342 \mathrm{c}$.

19. Смирнова Я.К., Белых А.С. Компоненты структуры регуляции совместной деятельности дошкольников // Инновации в науке : сб. стптей по материалам XLVI междунар. науч.-практ. конф. Новосибирск : СибАК, 2015. № 46. С. 105-112.

Поступила в редакцию 04.09.2017 2.; повторно 09.10.2017г.; принята 10.10.2017 г.

Сведения об авторе:

СМИРНОВА Яна Константиновна, кандидат психологических наук, доцент кафедры общей и прикладной психологии Алтайского государственного университета (Барнаул, Россия). E-mail: yana.smirnova@mail.ru

\section{ORIENTATIVE BASIS OF PRESCHOOL CHILDREN'S MUTUAL ACTIVITY}

Siberian journal of psychology, 2017, 66, 32-51. DOI: 10.17223/17267080/66/3

Smirnova Yana K., Altai State University (Barnaul, Russian Federation).

E-mail: yana.smirnova@mail.ru

Keywords: basic sequence of activities; orientation; orientative basis of mutual activity; structure of mutual activity; functional components; regulation of activities; preschool age.

The article is devoted to the phenomenon of the basic sequence of mutual activities as one of the mechanisms of organization and regulation of individual operations in mutual activities. It is shown that basic mutual activities of preschooler children reflect a program, which is a set of foreseen actions, united by a task and performed in a certain time and spatial sequence. The article confirms that in the basic part of actions the analysis of changes in the process of activity is carried out. In accordance with these changes in the reaction, the implementation of the program is regulated, and the conformity of the program and procedural process is not revealed.

The article describes an empirical study. We researched how to organize mutual activity of preschool children, to identify the special features of regulatory processes' arbitrariness that embodies in mutual activity through the main links of self-regulation system (orientation, planning, programming, modeling, evaluation of results). We have analyzed the basic sequence of mutual activities of preschoolers as one of the all-embracing mechanisms for coordinating the individual activity and the requirements of mutual activity.

We have marked the indicators of the basic sequence of activities, which are formed by combinations of generality, completeness, and the method of obtaining an orientative basis. These indicators have an impact on the effectiveness of mutual activities.

We have obtained the structure of preschool children's mutual activity. It includes several blocks, such as a block of orientative basis for mutual activities, a block of modeling, programming and retaining mutual executive actions, a block of motivational interest and control of mutual activity coordination. The block of orientative basis for mutual activities includes the informational basis of control and the reverse afference of funds allocation and coordination of mutual activities, through which the coordination of operational and technical aspects of activity with objective values of the problem situation components is achieved. 
The group's orientation in mutual activity in terms of its psychological content is a process of researching the conditions of forthcoming mutual activity and designing the means of its successful execution. The basic sequence of mutual activity acts as a structural part of this activity, directing and realizing the processes of interaction and coordination of actions.

The research confirms the contradictions associated with the need of reflecting the role of basic sequence of activities in operational planning in the context of mutual activities in setting tasks of different levels of novelty, complexity and uncertainty. The orientative part of a group's mutual activity (orientation) has been studied from the point of view of rethinking and expanding the notion of social and psychological criteria of effectiveness and ways to optimize the process of mutual activities integration with the criteria for voluntary regulation of activities. The obtained data confirm that based on the analysis of the orientation content, it is possible to reliably predict the progress and effectiveness of the forthcoming mutual activities of groups, to select and complete the groups for performing complex practical tasks.

\section{References}

1. Galperin, P.Ya. (1999) Vvedenie v psikhologiyu [Introduction to Psychology]. Moscow: KDU.

2. Welford, A.T. (1961) On the human demands of automation: Mental work conceptual model, satisfaction and training. Industrial and business psychology. 5. pp. 182-193.

3. Zinchenko, V.P. (1958) K voprosu o formirovanii orientiruyushchego obraza [On the formation of the orienting image]. In: Voronin, L.G., Leontyev, A.N. \& Luriya, A.R. (eds) Orientirovochnyy refleks $i$ orientirovochno-issledovatel'skaya deyatel'nost' [Orienting reflex and orienting-research activity]. Moscow: APN RSFSR. pp. 333-339.

4. Oshanin, D.A. (1973) Psikhologicheskie voprosy regulyatsii deyatel'nosti [Psychological questions of activity regulation]. Moscow: Pedagogika.

5. Chernyshev, A.S. (1980) Sotsial'no-psikhologicheskie osnovy organizovannosti pervichnogo kollektiva (na materialakh issledovaniya molodezhnykh grupp i kollektivov) [Socio-psychological foundations of the primary team organisation (on the study of youth groups and collectives)]. Abstract of Psychology Dr. Diss. Moscow.

6. Chernyshev, A.S., Sarychev, S.V. \& Lunev, Yu.A. (2005) Apparaturnye metodiki psikhologicheskoy diagnostiki gruppy $v$ sovmestnoy deyatel'nosti [Instrumental methods of psychological diagnosis of the group in joint activities]. Moscow: Institute of Psychology, Russian Academy of Sciences.

7. Zhuravlev, A.L. (2005) Psikhologiya sovmestnoy deyatel'nosti [Psychology of joint activity]. Moscow: Institute of Psychology, Russian Academy of Sciences.

8. Savchik, O.M. (2006) Orientirovochnaya osnova sovmestnoy deyatel'nosti kak uslovie sozdaniya volevogo edinstva gruppy [The approximate basis of joint activity as a condition for creating a strong-willed unity of the group]. Vestnik Polotskogo gosudarstvennogo universiteta. Seriya E: Pedagogicheskie nauki. 11. pp. 77-82.

9. Sarychev, S.V. \& Chernyshev, A.S. (2000) Sotsial'no-psikhologicheskie aspekty nadezhnosti gruppy $v$ napryazhennykh situatsiyakh sovmestnoy deyatel'nosti [Socio-psychological aspects of the group's reliability in tense situations of joint activity]. Kursk: Kursk State Pedagogical University.

10. Rubtsov, V.V. (1996) Osnovy sotsial'no-geneticheskoy psikhologii [Fundamentals of sociogenetic psychology]. Moscow: Institute of Practical Psychology; Voronezh: MODEK.

11. Gamova, E.I. (2009) [Study of socio-psychological aspects of the indicative framework of joint activities of small groups]. Lomonosov-2009 [Lomonosov-2009]. Proc. of the 16th International Youth Conference of Moscow State University. Moscow: MAKS Press. pp. 128-132. (In Russian).

12. Gamova, E.I. (2012) Orientirovka v strukture sovmestnoy deyatel'nosti i ee vliyanie na rezul'tativnost' sovmestnoy deyatel'nosti malykh molodezhnykh grupp [Orientation in the 
structure of joint activity and its impact on the effectiveness of joint activities of small youth groups]. Nauchnyy zhurnal KubGAU. 5(79). [Online] Available from: http://ej.kubagro.ru/2012/05/pdf/49.

13. Zaporozhets, A.V. (1986) Izbrannye psikhologicheskie trudy: $v 2 t$. [Selected psychological works: in 2 vols]. Vol. 2. Moscow: Pedagogika.

14. Endovitskaya, T.V. (1957) Vliyanie organizatsii orientirovochnoy deyatel'nosti na ob"em vnimaniya $\mathrm{u}$ detey [Influence of the organisation of orienting activity on the amount of attention in children]. Doklady APN RSFSR. 3. pp. 75-79.

15. Minskaya, G.I. (1954) Perekhod ot naglyadno-deystvennogo $k$ rassuzhdayushchemu myshleniyu u detey doshkol'nogo vozrasta [The transition from visual-effective to argumentative thinking in preschool children]. Abstract of Pedagogy Cand. Diss. Moscow.

16. Leontyev, A.N. (1981) Problemy razvitiya psikhiki [Problems of the psyche development]. Moscow: Moscow State University.

17. Luriya, A.R. \& Tsvetkova, L.S. (1966) Neyropsikhologicheskiy analiz resheniya zadach. Narusheniya protsessa resheniya zadach pri lokal'nykh porazheniyakh mozga [Neuropsychological analysis of problem solving. Violations of the problem solving process in case of local brain lesions]. Moscow: Prosveshchenie.

18. Talyzina, N.F. (1984) Upravlenie protsessom usvoeniya znaniy [Management of the learning process]. Moscow: Moscow State University.

19. Smirnova, Ya.K. \& Belykh, A.S. (2015) Komponenty struktury regulyatsii sovmestnoy deyatel'nosti doshkol'nikov [Components of the joint activity structure regulation in preschoolers]. Innovatsii v nauke. 46. pp. 105-112.

Received 04.09.2017;

Revised 09.10.2017;

Accepted 10.10.2017 